\title{
A New Website for Cartographic Resources - CartoMundi
}

\author{
Jean-Luc Arnaud \\ Director of research at the National Center for Scientific Research, \\ Maison méditerranéenne des sciences de l'homme, Aix-en-Provence, \\ llarnaud@mmsh.univ-aix.fr
}

\begin{abstract}
For about two years, the Maison Méditerranéenne des Sciences de l'Homme MMSH - in Aix-en-Provence has been developing a new website - CartoMundi dedicated to cartographic documents. This site is organised around a tool able to identify and select documents according to the geographical zone they really represent. Each series is described by a unique notice and a key map.

CartoMundi is a collective project; it consists of an open network of members. It will offer easy access to largely unknown documents and should encourage the use of cartography, both as a resource and as a research subject.
\end{abstract}

Key Words: CNRS; ADONIS; MMSH; key map; graphic index; map series; collective catalogue; GIS; digitised maps

The Maison Méditerranéenne des Sciences de 1'Homme - $\underline{\mathrm{MMSH}}$ — in Aix-en-Provence, numbering ten research centres in human and social sciences specialises in the Mediterranean region, and has a cross-disciplinary research topic dedicated to spatial representations. Its goal is to develop a long-term pool of competences for the use and the analysis of cartographic and iconographic documents. Its activities are organised in three main fields: research, training and production of research tools. Within this framework, a new website - CartoMundi - dedicated to cartographic documents, is being developed.

This programme finds its origin in the gap noticeable between metadata usually used to describe cartographic documents and the questions emanating 
from users who are looking for places. To reduce the gap, CartoMundi suggests adding to databases a geographic field which will be able to answer these questions. This field allows building a list of documents which represent a given place (punctual or territorial) identified though a simple click on a world map.

\section{A Profuse Production with an Inadequate Recording System}

Most of the maps and plans of towns and territories produced since the end of the 18th century are organised in series. Each series represents a specific place (town, region or country) at a specific time, on a relatively detailed scale, considering the size of the covered perimeter, which then needs to be published on very numerous sheets. For example, the map of France published by the Institut Géographique National numbers no less than one thousand sheets. Generally, these plans and maps have been produced by local, regional or national public authorities and their main goal is either the knowledge of and control over the territory for war purposes (the army is a great map producer) or the ability to plan infrastructure at every level, to record land property, or to calculate taxes (through cadastral maps). These documents are standardised and have not given rise to much interest among historians of cartography.

Nevertheless, it is obvious that these series are of exceptional value for academic work. They are not only important for retrospective geographical research, but for a vast number of studies in which researchers are curious about the spatial localisation of the phenomena they are analysing. However it is very difficult for researchers to use these documents. Their number renders their consultation difficult: finding your way around the 230 square metres of the map of France is no easy task. Furthermore, due to the number of sheets, the available catalogues do not render the territorial segmentation adequately.

Unlike periodicals, maps and plans series do not have a specific mode of cataloguing. The international system currently in use is adapted from the book cataloguing system: one entry corresponds to one document. This principle is relevant for individual maps, but it is not operative for map series because it is unable to indicate the geographical zone represented by each sheet, and cannot describe their editorial relation between the sheets. This drawback has two neg- 
ative implications for the use of the document. Whatever the field of research, the documents are difficult to use. Moreover, the standard mode of cataloguing is often neglected by the map curators themselves who prefer to keep printed files and key maps rather than to launch themselves in the long and tedious task of computerising data with an unsatisfactory result for users.

\section{A New Tool - Changing Scale}

In the light of this situation, it appeared necessary to develop a specific tool for map series - a tool able to identify and select documents according to the geographical zone they really represent. The most efficient method is well known: it is the key map or graphic index. For each series, the sheets' grid is printed on a base map with enough reference points to plot out the zone represented by each sheet. This method is not new, but until recently it was difficult to computerise. Thus, these key maps are often considered as a local appendix to the collections. On the contrary, in the system developed by CartoMundi, the graphic indexes are central. This entails a transformation of the cataloguing system: the unit is no longer a sheet but a series, itself described by a notice and a graphic index.

This method was first developed by the MMSH within an experiment on the mapping of Mediterranean towns and countries: La Cartothèque Méditerranéenne. This bilingual website, launched in September 2006, catalogues several thousands of maps depicting mainly the South and East of the Mediterranean basin, through the description of about 200 cartographic series. First of all, this index is independent from the place of storage of the maps and plans: each series is described fully from incomplete collections held by various libraries. Secondly, it is also a collective catalogue which allows an unlimited number of partners to report and to update the content of their collection.

Several French institutions have shown a great deal of interest in this project, especially the maps and plans department of the Bibliothèque nationale de France, the Institut géographique national, the Comité français de cartographie, the Réseau des bibliothèques universitaires de France, and the European network of social sciences research centres $\underline{\text { Ramses }}^{2}$. Moreover, the Centre national de la recherche scientifique (CNRS) has selected CartoMundi for its project $\underline{\mathrm{ADONIS}}$ aimed to improve access to computerised data. 


\section{Functioning through Stages and Networks}

CartoMundi consists in an open network of members, and its development follows four main stages.

\section{Setting up the Project}

The project combines a geographic information system with a data base management system and a graphic interface of data restitution. Housed in the MMSH in Aix-en-Provence, it is developed by the MMSH with the help of the ADONIS project and the TELEMME research centre. The project is supervised by two teams of experts: representatives of the Bibliothèque nationale de France, of the Comite français de cartographie and of the Institut géographique national who are concerned with the documentation, and scholars of several research centres who deal with computerised and geomatic cataloguing.

\section{Building the Index}

This stage is dedicated to the generic description of map series. The MMSH, with the help of the Ramses ${ }^{2}$ project, takes care of the maps and plans representing the Eastern and Southern Mediterranean countries. For the other parts of the world, it is necessary to develop partnerships with institutions with sufficient means to invest in the widening of the geographic scope covered by the project. National libraries, geographical societies, map libraries associations, map producing institutions, local or regional authorities, or universities could develop such a partnership.

\section{Collective Catalogue}

The collective catalogue is designed to include any interested institution, as long as it holds cartographic resources organised in series in libraries open to the public, and wishes to bring an added value to their collection through an innovative description mode. CartoMundi offers an interface through which, for each series of maps described in the index, they can enter online the content of their collection.

\section{Digitised Reproductions}

In the last few years digitised maps have grown in numbers which makes the navigation between files gradually more difficult. In this case again, the 
graphic index is the most efficient tool to select and visualise the documents. CartoMundi offers two different services. From its website, it puts online its own digitised documents or documents belonging to its members. It also develops links to other websites which offer online map series without any navigation tool between sheets.

CartoMundi seems to have interested map curators for its cataloguing system and management of documents which are simple to use. Moreover, it is also a tool for documentation, developed by scholars, for research purposes. It will offer easy access to documents which have been largely unknown, and should encourage the use of cartography, both as an information resource and as a research subject. In this way, it will contribute to one of the main objectives of the research programme: space, representation and use of the MMSH.

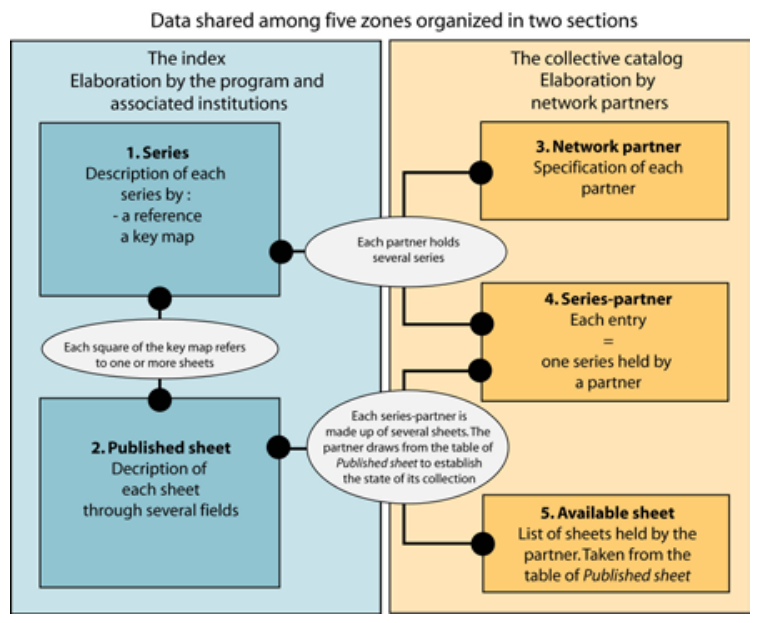

\title{
Websites Referred to in the Text
}

\author{
ADONIS, www.tge-adonis.fr/ \\ CartoMundi, http://cartomed.mmsh.univ-aix.fr \\ MMSH, Maison Méditerranéenne des Sciences de l'Homme, www.mmsh.univ-aix.fr/ \\ Ramses ${ }^{2}$ project, http://ramses2.mmsh.univ-aix.fr/ \\ TELEMME, www.mmsh.univ-aix.fr/telemme/
}

